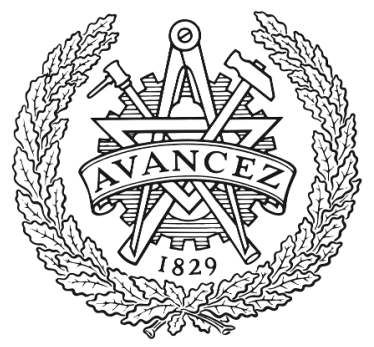

CHALMERS

UNIVERSITY OF TECHNOLOGY

\title{
Nonwoven geotextile scour protection at offshore wind parks, application and life cycle assessment
}

Downloaded from: https://research.chalmers.se, 2023-04-26 15:27 UTC

Citation for the original published paper (version of record):

Hoyme, H., Hao Su, J., Kono, J. et al (2019). Nonwoven geotextile scour protection at offshore wind parks, application and life cycle assessment. Scour and Erosion IX - Proceedings of the 9th International Conference on Scour and Erosion, ICSE 2018: 315-321

N.B. When citing this work, cite the original published paper. 


\title{
Nonwoven geotextile scour protection at offshore wind parks, application and life cycle assessment
}

\author{
Helge Hoyme \& Jong Hao Su \\ NAUE GmbH \& Co. KG, Espelkamp-Fiestel, Germany \\ Jun Kono \& Holger Wallbaum \\ Department of Architecture and Civil Engineering, Chalmers University of Technology, Gothenburg, Sweden
}

\begin{abstract}
The sand surrounding a construction (e.g. monopile) for mounting an offshore wind turbine, could be scoured due to the affection of natural water flow at the ocean floor. To tackle the phenomena, scour protection methods have been established. Mostly rocks are used, but also one alternative, described in this paper, has been used already successfully: The installation of Geotextile Sand Containers.
\end{abstract}

\section{INTRODUCTION}

Harvesting wind is still a growing industry as the price per kilowatt hour is high enough that even difficult locations for wind mills become attractive. An effective location for wind farming is offshore where the wind hardly stops blowing. The installation of such wind turbines is usually carried out using piles which are founded on or in the sea floor. Close to the sea floor are currents due to tidal streams or waves which lead immediately to scouring processes as soon as a fixed element is installed on a movable sea bed into the current. A process of scouring is unavoidable, independent on the type of pile or foundation.

This paper focusses on an Environmental Life Cycle Assessment according to ISO 14040/14044 of two alternative scour protection solutions - the conventional solution with rocks or an alternative method with sand-filled geotextile containersof a monopile system, as this system is used very often as an economic solution for the foundation of wind turbines. The assessment is conducted based on an existing case-study of a wind park in Germany. The analyses is followed by a discussion of the results including a sensitivity analysis. The content of this paper is also transferable for Jacket structures or any other types of foundation which have contact with the mobile sea bed.

\section{CONVENTIONAL SCOUR PROTECTION}

The conventional scour-protection method is usually carried out by a filter layer and an armor stone layer. The filter layer is necessary to avoid the armor stone layer to sink into the fine sea bed material.

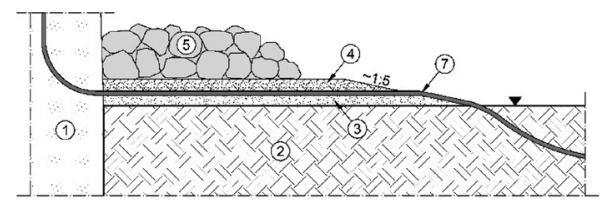

(1) Pile of OWP, (2) sea bed, (3) filter layer, (4) gravel layer, (5) rock armour, (7) sea cable

Figure 1. Rock scour protection.

After installation, the filter layer will be covered by an armor layer (rock classes, rip-rap) which is needed to protect the filter layer and the fine material on the sea bed underneath against scouring due to the hydrodynamic forces. This method requires large quantities of stone placed on the natural marine sand seabed. The stones required are often quarried far away from the location of the offshore wind park (OWP) and have to be transported at considerable costs to the locations of the projected OWP.

After piling the mast through the sea bed or through the already installed filter layer, the installation of the armour rocks must be carried out on short notice, otherwise the hydrodynamic forces will scour the sea bed or the already installed filter layer in a very short time, depending on the strength of the hydrodynamic forces at the particular location.

\section{GEOTEXTILE SCOUR PROTECTION}

Geotextile Sand Containers (GSC) used as scour protection system are assembled of untreated, mechanically bonded nonwovens. As an example, the scour protection of an Offshore Wind Park (OWP) in the North Sea are filled with approxi- 
mately $1 \mathrm{~m}^{3}$ of sand (weight per sand container: approximately $1.4 \mathrm{t}$ ). Geotextile sand-filled containers (GSC) successfully and permanently replace multi-layer granular filter and stone riprap layers. Before installation, sand containers constructed in this manner, consist of $99.65 \%$ by weight of sand (inert substance) and to approx. $0.35 \%$ of geotextiles (polypropylene fibers). The characteristics of a nonwoven geotextile with a unit weight of approx. $650 \mathrm{~g} / \mathrm{m}^{2}$, a thickness of $6 \mathrm{~mm}$, an opening size of $0.08 \mathrm{~mm}$ and a pore volume of $90 \%$ lead to the nonwoven being penetrated by sediment particles, so that the surface of the geotextile is comparable to a layer of fine sand intermingled with fibers. The GSC are installed beforehand of the installation of the monopile of the turbine, the monopile is piled right through the layer of GSC placed on the sea bed. Under installed conditions geotextile sand containers made of needle-punched nonwovens form a barrier-free layer system of pores, sediment pores, interlocked fibers, sand and water.

One big advantage of using the geotextile sand containers as scour protection is that they can be installed before piling the mast of the turbine. The GSC system works as a filter and armor system in one piece. The GSC's can be installed randomly on the floor of the sea bed in two layers and the mast can be piled right through the scour protection system.

\section{LIFE CYCLE ANALYSIS}

An environmental assessment comparing two systems must be based on a comprehensive analysis of their ecological performance. The life cycle assessment of the scour protection covered in the paper

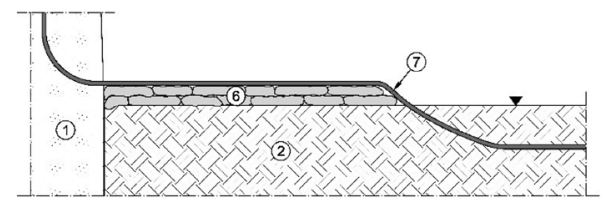

(1) Pile of OWP, (2) sea bed, (6) geosynthetic scour protection, (7) sea cable

Figure 2. GSC scour protection. represent four existing cases of offshore wind parks, one based on Geosynthetic bags filled with sand and three conventional solutions based on an armor layer of rocks.

\section{$4.1 \quad$ Functional unit}

The function of the scour protection for an offshore wind park is to avoid the scouring around the foundation (e.g. monopile) of the wind turbine. Thus, the functional unit of the study is defined as one piece of solution to protect $6 \mathrm{~m}$ diameter monopile from scouring.

\subsection{System boundaries}

The Life Cycle Analysis in this paper is carried out following the cradle to grave approach. This analysis corresponds to module $\mathrm{A}$ to module $\mathrm{C}$ in EN 15804 (European Committee for Standardization 2013). The product systems of the infrastructure elements analyzed in the study encompass the extraction of the raw materials, its processing to building materials, installation, operational and end-of-life phase of the infrastructure elements. The operational and end-of-life phase was considered to have no maintenance nor disposal, except for the land occupation. The life time of the system was considered to be 25 years. Transportation processes and infrastructure are included in a respective manner. Manufacturing and installation processes represent site specific conditions while the rest represents average European conditions.

Not included are:

- Manufacturing equipment (machinery) at the manufacturer's site, because of its minor importance, see e.g. (Frischknecht et al. 2007).

- Operation of the storage of raw and geosynthetic materials at the manufacturer's site, because the energy consumption is considered negligible (Stucki et al. 2011).

\subsection{Cut-off rules}

The study includes the inputs to a feasible extent. The equipment used in geosynthetics manufacture is excluded because of its low importance.

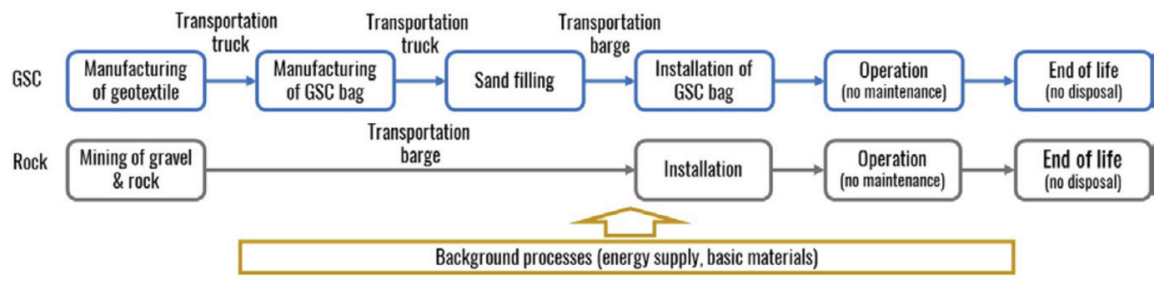

Figure 3. Simplified process flow chart of the two scour protection solutions: with geotextile sand container (GSC) and with rock. The simplified chart shows the most important process steps. 


\subsection{Life cycle impact assessment}

The following explanation of the life cycle impact assessment mainly refers to (Stucki et al. 2011). The main difference from their study is the inclusion of USEtox to include the impact on human health, to see the impact in a holistic manner.

The environmental performance of this study is assessed with the following impact category indicators:

- Cumulative Energy Demand (CED), Primary Energy Consumption, split into non-renewable and renewable fractions,

- Abiotic Depletion Potential,

- Climate Change (Global Warming Potential, GWP100),

- USEtox,

- Photochemical Ozone Formation,

- Acidification,

- Eutrophication.

This set of indicators enables a comprehensive analysis of the environmental performance of the product systems under study and the shift of environmental burdens is likely to be avoided. Cumulative energy demand is used to get insights into the efficiency of using energy resources while Abiotic Depletion Potential allows to get insights on non-energy resources. Climate change is considered because of their large environmental damage potential and their importance in international environmental policy. USEtox is chosen to quantify the impact on eco- and human-toxicity. The remaining impact category indicators reflect emissions occurring during extraction and preparation of the raw materials (gravel and plastics) and during transportation.

In the following sections the category indicators are described.

\subsubsection{Cumulative Energy Demand (CED)}

The CED (implementation according to (Frischknecht et al. 2007)) describes the consumption of fossil, nuclear and renewable energy sources along the life cycle of a good or a service. This includes the direct uses as well as the indirect or grey consumption of energy due to the use of, e.g. plastic or wood as construction or raw materials. This method has been developed in the early seventies after the first oil price crisis and has a long tradition (Pimentel et al. 1973; Boustead and Hancock 1979). A CED assessment can be a good starting point in an environmental impact assessment due to its simplicity in concept and its comparability with CED results in other studies. In this study, the CED indicator is used as a resource indicator.

The following two CED indicators are calculated:

- CED, non-renewable [MJ-eq.] - fossil and nuclear
- CED, renewable [MJ-eq.] - hydro, solar, wind, geothermal, biomass.

\subsubsection{Global Warming Potential 2013 (GWP)}

All substances, which contribute to climate change, are included in the global warming potential indicator according to IPCC (IPCC 2013). The residence time of the substances in the atmosphere and the expected emission design are considered to determine the global warming potentials. The potential impact of the emission of one kilogram of a greenhouse gas is compared to the potential impact of the emission of one kilogram $\mathrm{CO}_{2}$ resulting in $\mathrm{kg} \mathrm{CO}_{2}$-equivalents. The global warming potentials are determined applying different time horizons (20, 100 and 500 years). The short integration period of 20 years is relevant because a limitation of the gradient of change in temperature is required to secure the adaptation ability of terrestrial ecosystems. The long integration time of 500 years is about equivalent with the integration until infinity. This allows monitoring the overall change in temperature and thus the overall sea level rise, etc.

In this study a time horizon of 100 years is chosen, which is also used in the Kyoto protocol.

\subsubsection{USEtox}

USEtox is an impact assessment methodology to assess the impact on human health and on freshwater along the life cycle of a product. The method is a scientific consensus method, which has been developed through UNEP/SETAC Life Cycle Initiative for harmonization among various available methods (Rosenbaum et al. 2008). Through the assessment with USEtox $v$ 1.04, impacts from emission on non-cancer and cancer related human health impact and on ecotoxicity in freshwater can be assessed. The human health impact is quantified as disability adjusted life year (DALY). DALY quantifies the potential reduced quality of life due to illness or disabilities that occur due to the emissions. The impact on ecotoxicity in freshwater is expressed as a potentially disappeared fraction (PDF) of freshwater species integrated over exposed volume and time [PDF $\left.\mathrm{m}^{3} \mathrm{~d}\right]$.

\subsubsection{Further environmental impact category indicators}

The remaining category indicators considered in this study derive from the CML-IA method (Guinée 2002). They are described in the following.

- Acidification $\left[\mathrm{kg} \mathrm{SO}_{2}\right.$ eq] describes a change in acidity in the soil due to atmospheric deposition of sulphates, nitrates and phosphates. Major acidifying substances are $\mathrm{NO}_{\mathbf{x}}, \mathrm{NH}_{3}$, and $\mathrm{SO}_{2}$. This covers all relevant substances as in the foreground system no emissions of other acidifying 
substances as $\mathrm{HCl}, \mathrm{HF}$, etc. occur. Derived from CML.

- Eutrophication $\left[\mathrm{kg} \mathrm{PO}_{4}^{3-}\right.$ eq] can be defined as nutrient enrichment of the aquatic environment. In inland waters eutrophication is one of the major factors that determine its ecological quality. Derived from CML.

- Photochemical oxidation [kg ethane eq] - average European ozone concentration change, also known under "summer smog". Photo-oxidant formation is the photochemical creation of reactive substances (mainly ozone), which affect human health and ecosystems. This ground-level ozone is formed in the atmosphere by nitrogen oxides and volatile organic compounds in the presence of sunlight. Derived from CML.

\subsection{Limitations of the study}

The life cycle assessments of the scour protection covered in the study represent the before mentioned four cases of offshore wind parks, one based on Geosynthetic bags filled with sand and three solutions based on rock. This limits the generalization of the study results as construction methods may vary depending on the regions. Nonetheless, the cases could be considered as best representative common industrial measures, according to the inputs from the experienced industrial partners for this study.

Due to the nature of LCA as an assessment methodology, the results of the LCA's do not fully allow answering the question whether or not constructions based on geosynthetic materials are generally the environmentally preferable option. Site specific measured information, which environmental risk assessment or other types of environmental impact assessment may collect, is generally not part of LCA studies. Additional information and application of different methodologies may require to fully allow concluding the environmental competitiveness of certain types of construction solution for scour protection. One of such studies to complement the LCA results could be the environmental impact assessment from (E.ON Climate and Renewables 2012).

\subsection{Characterisation of the scour protection solutions}

The study investigated two solutions for scour protection: using geotextile sand container (GSC); and the conventional one using rocks. The life cycle stages covered in the study is from cradle-to-grave, which corresponds to A1 to C4 module of EN 15804 (European Committee for Standardization 2013). The base scenario for the two solutions were considered to have no maintenance during the 25 years of operational lifetime of the monopile. For the end-of-life treatment, the two protection solutions were considered to be left as it is on the ocean floor which is expected to become part of the ecosystem under ocean.

\subsubsection{GSC scour protection}

The case for using GSC scour protection was taken from an actual completed case in North Sea. The offshore wind park (OWP) Amrumbank West was selected for the assessment. The OWP details are presented in Table 1. Polypropylene granules are used as the basic material for the geosynthetics used for GSC. The geosynthetics used for the bag was Secutex ${ }^{\circledR}$, which the average weight of the product was $600 \mathrm{~g} / \mathrm{m}^{2}$.

The installation of GSC's are executed prior to monopile driving, the design specifics of the solution are described in Table 2.

\subsubsection{Rock scour protection}

As the conventional scour protection solution, rock (gravel) has been used. The study looked into three cases of rock scour protection, namely OWP Amrumbank West, OWP Rampion in the UK and OWP Riffgat in Germany. In this solution, two layers are typically constructed, filter layer and the armor layer. In Table 3, main design features of the three investigated rock scour protection solution are described.

\subsection{Life cycle inventory}

A general description of the infrastructure element and the geosynthetic layers is given in the following sections.

Table 1. Project details of GSC scour protection application.

\begin{tabular}{ll}
\hline Content & Details \\
\hline Client & E.ON Climate \& Renewables \\
Location & North Sea \\
Project Area & $32 \mathrm{~km}^{2}$ \\
Number of Turbines & 80 \\
Installed Capacity & $302 \mathrm{MW}$ \\
Distance to Shore & $33 \mathrm{~km}$ \\
Start Offshore Activities & Apr-12 \\
Completion & 2015 \\
\hline
\end{tabular}

Table 2. Design specifics of GSC scour protection.

\begin{tabular}{ll}
\hline Content & Details \\
\hline Project name & OWP Amrumbank West \\
Height & $0.90 \mathrm{~m}$ \\
Mean Diameter & $24.00 \mathrm{~m}$ \\
Required Volume per & $410 \mathrm{~m}^{3}$ (500 GSC bags) \\
$\quad$ Location & \\
\hline
\end{tabular}


Table 3. Design specifics of rock scour protection.

\begin{tabular}{llll}
\hline Project name & OWP AmrumbankWest & OWP Rampion & OWP Riffgat \\
\hline Height (Filter and Amour Layer) & $0.80+1.60=2.40 \mathrm{~m}$ & $0.50+1.00=1.50 \mathrm{~m}$ & $0.70+0.85=1.55 \mathrm{~m}$ \\
Monopile Diameter (D) & $6 \mathrm{~m}$ & $6.5 \mathrm{~m}$ & $5.7-6.5 \mathrm{~m}$ \\
Mean Diameter ( 4xD) & $24.4 \mathrm{~m} / 33.8 \mathrm{~m} / 38.6 \mathrm{~m}$ & $32.5 \mathrm{~m} / 38.5 \mathrm{~m}$ & $35 \mathrm{~m}$ \\
Required Volume per Location & $1,100+1,000=2,100 \mathrm{~m}^{3}$ & $550+1,000=1,550 \mathrm{~m}^{3}$ & N/A $(1300 \mathrm{t}+1000 \mathrm{t})$ \\
\hline
\end{tabular}

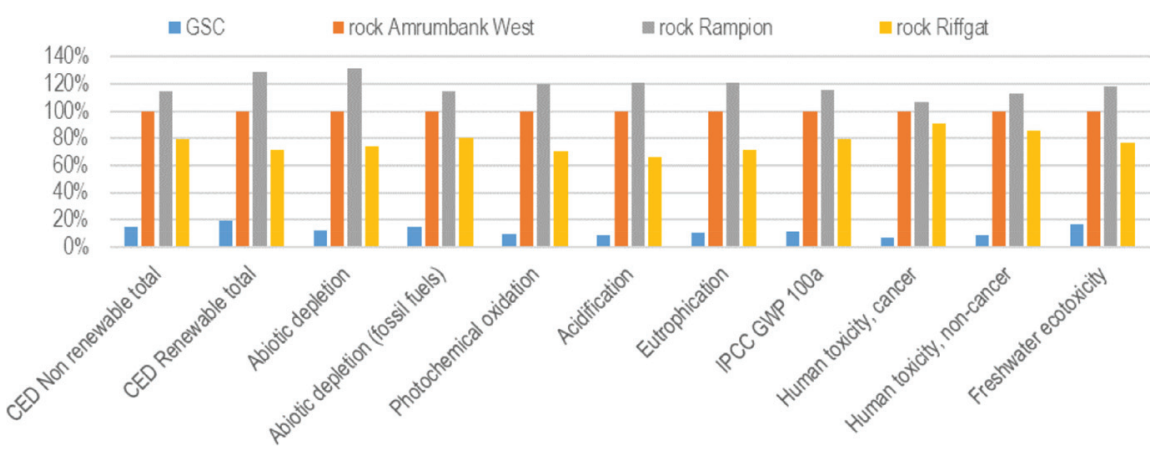

Figure 4. The cradle-to-grave environmental impacts of scour protection solutions per monopile. For each indicator, the case of rock scour protection solution at Amrumbank West is scaled to $100 \%$.

\subsubsection{LCI of case 1}

In this case, geotextile produced from NAUE was sawn and sewed into GSC bags and transported to Römö, Denmark, by lorry. The bags were filled with sand at the site and transported by a barge for $100 \mathrm{~km}$ and installed by using vessels. The installation was considered to take 6 months, $20 \%$ machine operational time and 12 hours per day.

\subsubsection{LCI of case 2}

For the three investigated conventional scour protection cases, the main inventory types were the same, although the value itself differed. The process flow of the rock scour protection solution started with gravel extraction, where the extraction site was specified as Norway (E.ON Climate and Renewables 2016). This gravel was then shipped to the installation site, where the installation activity was made 24 hours per operation day, with having 4.5 operational days per cycle. In total, the installation was considered to be completed after 18 cycles.

\subsection{Results of LCIA of scour protection}

This section illustrates the result of LCIA of two scour protection systems, where the rock scour protection system is represented by three different cases. In Figure 4, the LCIA result of the full life cycle of the two solution is given, where each environmental impact is scaled to $100 \%$ based on the impact of rock scour protection at Amrumbank West. The result showed clear environmental competitiveness of the GSC scour protection system for all the investigated impact categories.

The difference of impacts among the rock scour protection solution between the three investigated cases was ranging from $-35 \%$ to $+32 \%$ depending on the impact category. Even with this variation among the conventional solution, the environmental competitiveness of GSC solution was much better than the rock protection solution, which the impact of GSC ranged from $8 \%$ to $27 \%$ of the impact of the best performing conventional solution (Rifgatt).

\subsection{LCIA sensitivity analysis}

For the sensitivity analysis of this study, two aspects were considered. The first aspect is about the endof-life (EoL) treatment of GSC scour protection solution. The second is about the allocation rule of the LCA, using recycled content approach which is available in Ecoinvent v3 (Weidema et al. 2013).

The base scenario of the study considered the EoL phase of the two solutions to be left on the ocean floor, since the majority of the materials used for the two solutions are minerals. However, as GSC contains a plastic material, a sensitivity analysis of the EoL phase for the GSC scour protection 
was considered. As the scenario for EoL treatment of GSC case, incineration was considered. The operation for removing the GSCs were considered to require 2 months, 6 hours per operational day per vessel, with $50 \mathrm{~km}$ of lorry transportation to waste incineration facility.

In LCA, several rules and methods exist to quantify the impact of a product or service. One of such rules are the allocation methods. LCA allocation methods deals with how the impact of recycled products are quantified. While allocation at the point of substitution (APOS) shares the burden between the impact caused for producing the recyclable material and its recycling treatment process between the primary use and the secondary use, recycled materials in recycled content approach carries no environmental burden (Wernet et al. 2016). The difference on how environmental impacts are allocated between the production illustrates how the APOS allocation is made. Thus, the study carried out a sensitivity analysis on the two different allocation methods available in ecoinvent.

In Figure 6, the results of sensitivity analysis of LCIA of the two solutions are shown, which
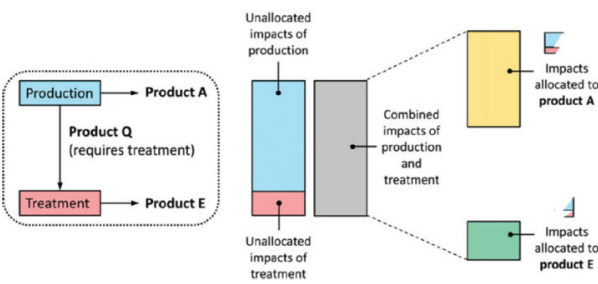

Figure 5. Overview of APOS model. How the impact of primary material and the secondary material are allocated are illustrated (source: Wernet et al. 2016). is again scaled to $100 \%$ by taking rock solution at Amrumbank West as reference for all the impact categories. The results illustrate the marginal influence of EoL treatment of GSC on the competitive environmental advantage against conventional solution. The occurred difference on each impact categories between the GSC base case and the three sensitivity analysis was ranging from $-2.6 \%$ to $26 \%$ of the GSC base case $(-0.5 \%$ to $3.8 \%$ by taking the rock solution at Amrumbank West as the reference). Moreover, the influence of the allocation method was more observed for the conventional scour protection solution than the GSC one in the figure. The result of the sensitivity analysis confirmed the clear advantage of GSC solution with the considered scope of sensitivity.

\subsection{Contribution analysis GSC scour protection}

In this section the environmental impacts of the base case GSC scour protection (no EoL treatment) per monopile is evaluated in detail. Included are the provision and use of raw materials, working materials, energy carriers and infrastructure. The category GSC bag in Figure 7 includes the direct burdens of the production of Secutex ${ }^{\circledR}$, materials and electricity for sewing the textile. This includes land occupied to produce the geosynthetic.

The contribution analysis of cradle-to-grave environmental impact of a base case GSC scour protection is shown in Figure 7. The environmental impacts of the GSC scour protection was mostly dominated by the filled sand for the majority of the considered environmental impact categories. The impact category where the sand had the highest share was on the resource efficiency of raw material, shown as Abiotic depletion. The impact of GSC was seen in fossil energy related indicators,

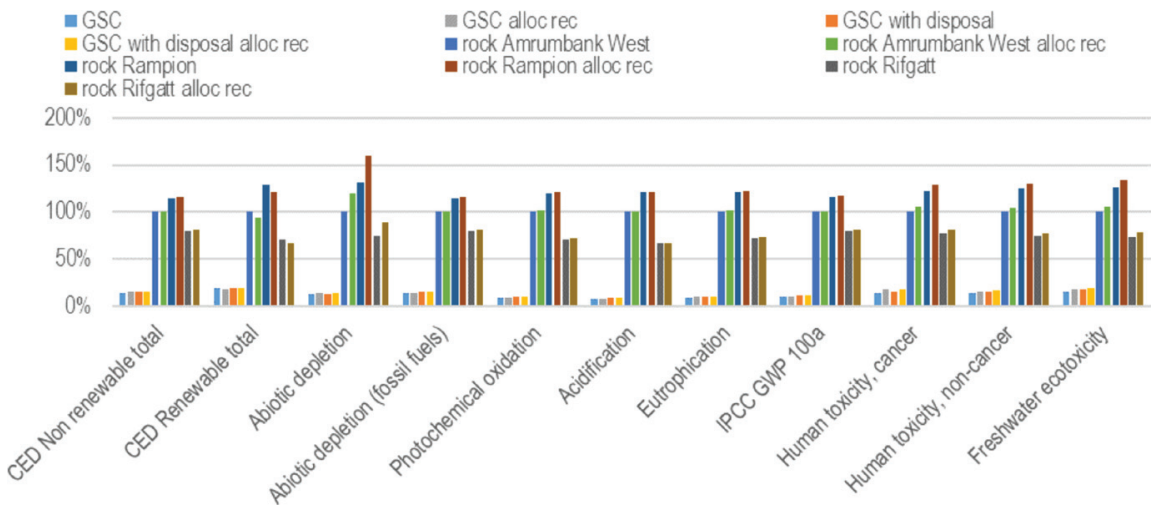

Figure 6. Sensitivity analysis of environmental impacts of scour protection solutions per monopile. "Alloc rec" represents recycled content allocation approach, while others adhere allocation at the point of substitution approach which is the default approach in Ecoinvent v3. The "disposal" includes the waste treatment scenario of GSCs. 


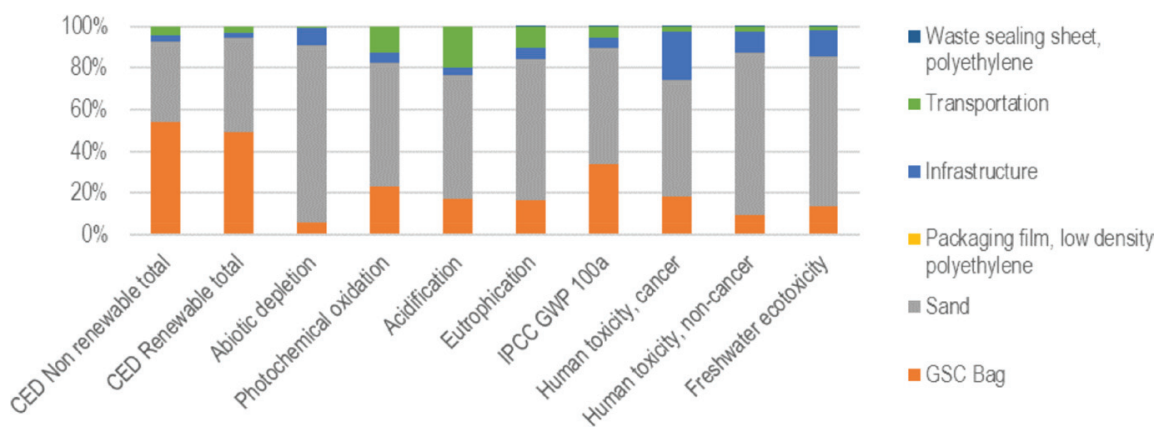

Figure 7. The contribution analysis of cradle-to-grave environmental impacts of GSC scour protection.

such as CED (both non-renewable and renewable) and on $\mathrm{CO}_{2}$ emission shown as GWP.

In regards to the impact on human health, the infrastructure was showing larger impact than the other impact categories. This infrastructure category represents the machine operation and infrastructure of all phases after the GSC bag manufacturing.

\section{DISCUSSION AND CONCLUSION}

The investigation on environmental impact of the two scour protection solutions - the use of GSC and conventional rock - on offshore wind parks resulted with a clear advantage of the GSC solution for the considered impact categories. The advantage of environmental performance of GSC solution remained the same when assessing three different offshore wind park sites, where the volume of used rock differed. The sensitivity analysis of including the waste treatment for the GSC solution and the application of different LCA allocation method was performed, all resulting with GSC as a superior scour protection solution in terms of environmental friendliness among the covered scope.

Detailed investigation on the cause of impact of GSC scour protection revealed that filled sand was responsible for a large share of the impact on most of the categories. Impact categories where GSC had larger share was on energy related indicators, such as CED and GWP.

Despite the necessary simplifications and assumptions, the results of the comparison are considered to be significant and reliable.

\section{REFERENCES}

E.ON Climate and Renewables (2012) Rampion Offshore Wind Farm Environmental Statement.
E.ON Climate and Renewables (2016) Notice to Mariners: Rampion Offshore Wind Farm.

Frischknecht R, Jungbluth N, Althaus H-J, et al. (2007) Implementation of Life Cycle Impact Assessment Methods. Dübendorf.

Grosser, D. et al., (2014) Design, Installation and Monitoring of a Geotextile Scour Protection for the Offshore Wind Farm Amrumbank West. 10th ICG, Berlin, September 21-25, 2014.

Guinée JB (2002) Handbook on life cycle assessment: operational guide to the ISO standards. Kluwer, Dordrecht.

IPCC (2013) Climate Change 2013: The Physical Science Basis. Contribution of Working Group I to the Fifth Assessment Report of the Intergovernmental Panel on Climate Change. Cambridge University Press, Cambridge, United Kingdom and New York, NY, USA.

Peters, K. \& Werth, K. (2012) Offshore Wind Energy Foundations - Geotextile Sand-Filled Containers as Effective Scour Protection Systems. 6th International Conference on Scour and Erosion, Paris, pp 823-830, August 27-31, 2012.

Rosenbaum RK, Bachmann TM, Gold LS, et al (2008) USEtox - The UNEP-SETAC toxicity model: recommended characterisation factors for human toxicity and freshwater ecotoxicity in Life Cycle Impact Assessment. Int J Life Cycle Assess 13:532-546. doi: 10.1007/s11367-008-0038-4.

Stucki M, Büsser S, Itten R, et al (2011) Comparative Life Cycle Assessment of Geosynthetics versus Conventional Construction Materials. Kanzleistr. 4, CH-8610 Uster, Switzerland.

Weidema BP, Bauer C, Hischier R, et al (2013) The ecoinvent database: Overview and methodology, Data quality guideline for the ecoinvent database version 3 .

Wernet G, Bauer C, Steubing B, et al (2016) The ecoinvent database version 3 (part I): overview and methodology. Int J Life Cycle Assess 21:1218-1230. doi: 10.1007/s11367-016-1087-8. 